\title{
Genetic Structure and Analysis of Host and Nonhost Interactions of Striga gesnerioides (Witchweed) from Central Florida
}

\author{
Christopher J. Botanga and Michael P. Timko
}

Department of Biology, University of Virginia, Charlottesville 22904.

Accepted for publication 24 May 2005.

\begin{abstract}
Botanga, C. J., and Timko, M. P. 2005. Genetic structure and analysis of host and nonhost interactions of Striga gesnerioides (witchweed) from central Florida. Phytopathology 95:1166-1173.

Striga gesnerioides is a root hemiparasite of wild and cultivated legumes, among which cowpea (Vigna unguiculata) and Indigofera hirsuta are suitable hosts. In this study, we examined the genetic structure and host-parasite interaction of a strain of $S$. gesnerioides parasitizing I. hirsuta (SGFL) from central Florida (United States). Amplified fragment length polymorphism analysis was used to compare genetic profiles from 71 individual $S$. gesnerioides plants (SGFL) representing four different populations in central Florida. Our results showed that these individuals are genetically similar, with pairwise genetic distances ranging from 0.00 to 0.037 . A cluster analysis grouped all four $S$. ges-

One EcoRI and MseI selective primer combination generated a 510-bp fragment present in individuals from the SGFL and the West African isolate parasitic on I. hirsuta, but absent in isolates parasitic on cowpea. Germination of seed from individuals of all four populations of $S$. gesnerioides parasitic on I. hirsuta from Florida was stimulated by root exudates from cowpea genotypes Blackeye and TVX-3236, known to be highly susceptible to all races of $S$. gesnerioides parasitic on cowpea in West Africa. SGFL seedlings failed to parasitize cowpea, with the development of attached SGFL seedlings arrested at the tubercle stage. The very high level of genetic uniformity observed within and among the central Florida populations suggests that there was likely a single introduction of the parasite or strong host-driven selection to genetic uniformity. These findings are important in assessing the potential of the parasite as an agronomically significant pest in the United States.
\end{abstract} nerioides populations from Florida, separating them from $S$. gesnerioides isolates parasitic on I. hirsuta and cowpea collected from West Africa.
Additional keywords: germination stimulation, incompatibility.
The genus Striga (family Scrophulariaceae) is composed of $\approx 50$ species, most of which are obligate parasites of tropical cereals and legumes (7). The most agronomically important species of the genus are $S$. hermonthica (Del.) Benth, S. asiatica (L.) Kuntz, and $S$. gesnerioides $(5,33)$. All three species associate intricately with their hosts and constitute a serious threat to food crop production in Africa (24) by parasitizing the roots of crop plants and serving as water and nutrient sinks (35). S. hermonthica and S. asiatica are most devastating on cereal crops. In West Africa, they cause serious yield losses to staple food crops such as corn (Zea mays), sorghum (Sorghum bicolor), upland rice (Oryza sativa), and pearl millet (Pennisetum glaucum) (1). S. gesnerioides, on the other hand, attacks cowpea (Vigna unguiculata), and results in $100 \%$ yield loss in some instances (16). It also is reported to attack tobacco (Nicotiana tabacum) in South Africa $(28,41)$.

Through an elegant system of chemical signaling, Striga spp. recognize a potential host plant and regulates its development in order to optimize its chances for survival. Germination, haustorial induction, attachment to, and penetration of the host vascular system are all critical events in the Striga life cycle. Striga seed are nearly microscopic, averaging $\approx 0.3$ by $0.2 \mathrm{~mm}$ and weighing $6 \mu \mathrm{g}$ (31), with each plant capable of producing between 50,000 and 500,000 seed (1) per generation. Prior to germination, the seed must undergo an after-ripening period of $\approx 2$ to 3 months. This after-ripening period must be followed by a preconditioning period during which the seed imbibe water at a suitable temperature (44) of $\approx 27$ to $30^{\circ} \mathrm{C}$ for at least 7 days. Seed germination in $S$. hermonthica and $S$. asiatica has been reported to increase with

Corresponding author: M. P. Timko; E-mail address: mpt9g@ virginia.edu

DOI: 10.1094/PHYTO-95-1166

(C) 2005 The American Phytopathological Society the length of preconditioning period for up to 3 weeks $(2,6,44)$. The final step for germination to proceed is the exposure of the preconditioned seed to a specific chemical signal produced by the host roots $(36,44)$. An array of molecules which differ in chemical structure and specific activity stimulate the germination of Striga seed $(4,10,18,44)$. Following germination, a second host-derived chemical signal from the root, known as the haustoria initiation factor (HIF), is required for the differentiation of the radicle into the haustorium, by which the Striga seedling attaches to and penetrates the host root $(7,13,34)$. When the vascular connection is established between the host and the parasite following penetration of the stele by the haustorium, the development of the haustorium ceases $(13,37)$. As the vascular connection is established, the Striga seedling enlarges, forming a thick mass of tissue called the tubercle. This structure, which may be irregular in shape, enlarges as it differentiates.

Approximately half of the Striga life cycle is underground, during which time much of the damage to the crop host occurs, in part, through the diversion of host resources to the parasite. It has been estimated that the loss of carbon from the host by export to the parasite is more important than reduced photosynthetic capacity of the host imposed by the parasite in accounting for observed reduction in host growth in the cowpea-S. gesnerioides interaction (19). The damage done to the crop host is greater than can be explained by nutrient diversion alone. It is reported that the exchange of chemicals is bi-directional and that the parasite possibly releases some toxins that inhibit the growth and development of the host $(15,19,20)$. This argument is supported by the fact that a small portion of ${ }^{14} \mathrm{C}$-labeled $\mathrm{CO}_{2}$ taken up by photosynthetically active Striga plants eventually could be traced in the host plant (35). Also, in vitro culture studies revealed that, after establishment on the host root, the host plant provides the parasite not only moisture, minerals, and photosynthate, but also addi- 
tional chemical signals required for further growth and development (8). Once above ground on a compatible host with adequate moisture, the parasite grows rapidly to produce numerous seed that can remain viable in the soil for well over a decade.

Morphological variation exists within $S$. gesnerioides, with isolates from various locations distinguishable by stem succulence, internode length, flower color, and size (26-28,31). Field observations also suggest that certain morphotypes may differ in their host specificity $(25,28,31)$.

S. gesnerioides was first reported in the United States in 1980, from Polk County, Florida (22). This strain of S. gesnerioides (designated as SGFL) is distributed in five counties in central Florida where it mainly parasitizes Indigofera hirsuta and, less frequently, small-flowered morning glory (Jacquemontia tamnifolia) and one-leaf clover (Alysicarpus vaginalis) (28). Sunflower (Helianthus annuus) and sweet potato (Ipomea batatas) also have been reported to support the growth and flowering of SGFL in pot tests, although there are no reports of such attacks under field conditions (28).

The current distribution and host range of $S$. gesnerioides in the United States is not known, and there has not been any attempt to analyze the genetic variation within this strain, or the possibility of this parasite becoming an agronomically significant pest in the United States. As a result of its autogamous mode of reproduction, minimal disturbance, and the seclusion from its counterparts in Africa and Asia, the S. gesnerioides from central Florida offers an interesting system to study species evolution. In this study we report the first attempt to determine the genetic structure and variability of the Florida strain of $S$. gesnerioides at the molecular level. We also examine and report on the germination and postattachment interaction of this strain with host and nonhost species.

\section{MATERIALS AND METHODS}

Terminology. In this study, we use the term "strain" to refer to isolates of $S$. gesnerioides that are adapted to parasitize a specific host species. The strain of $S$. gesnerioides that parasitizes Indigofera hirsuta in Florida is designated as SGFL. A race is defined as a host species-specific variant, distinguishable by its differential ability to parasitize cultivars of the same host species. There are six defined races of the West African strain of $S$. gesnerioides that parasitize cowpea and are designated as SG1 to SG6.

Field collection of plant materials and seed. Four independent collections were made of $S$. gesnerioides plants parasitizing I. hirsuta in and around Ft. Meade, FL (81 ${ }^{\circ} 56.62^{\prime}$ and $27^{\circ} 47.03^{\prime}$ ) in fall 2001 . The collection sites were separated by at least $10 \mathrm{~km}$. The different populations sampled are designated SGFL1, SGFL2, SGFL3, and SGFL4. At each site, S. gesnerioides seed were collected in bulk and grown on I. hirsuta in the laboratory to obtain fresh plant tissue for DNA extraction. In addition, 56 individual $S$. gesnerioides plants and mature seed were collected from the SGFL1 population and maintained separately on an individual plant basis for later use. The vegetative tissues were placed in polyethylene bags and immediately kept on dry ice overnight and sent to the University of Virginia, Charlottesville. Upon arrival, samples were removed and kept at $-80^{\circ} \mathrm{C}$ for long-term storage until DNA extraction. All seed and plant materials were handled according to APHIS requirements.

Growth and preparation of plant and seed materials from S. gesnerioides in the laboratory. Following an after-ripening period of 3 months, the bulk-collected seed for SGFL2, SGFL3, and SGFL4 were threshed. Approximately 500 S. gesnerioides seed were infested in 6-in. plastic pots containing 30:70\% (vol/vol) Metro-Mix250 (Scotts-Sierra Horticultural Product Company, Marysville, $\mathrm{OH}$ ) and sand. Each collection was used to infest 12 pots (replications) and planted with six I. hirsuta seed (purchased from Wise Seed Co. Inc., Frostproof, FL). The number of I. hirsuta seedlings per pot was reduced to 4 at 2 weeks postplanting. At 15 weeks postplanting, emerged individual S. gesnerioides plant tissues were collected, flash frozen in liquid nitrogen, and stored at $-80^{\circ} \mathrm{C}$ until used for DNA extraction.

DNA extraction and amplified fragment length polymorphism profile analysis. Total genomic DNA was extracted from individual $S$. gesnerioides plants using the cetyltrimethylammonium bromide method as described previously (40), with the exception that a double phenol/chloroform precipitation was employed in order to remove phenolic compounds not removed during the first precipitation. Amplified fragment length polymorphism (AFLP) analysis was performed essentially as described previously (42), with some modifications. A selective amplification using $1 \mu \mathrm{l}$ of a 10 -fold dilution of the pre-amplification product was carried out using pairwise combinations of $\left[\gamma^{-32} \mathrm{P}\right]-$ ATP (Perkin-Elmer Inc., Boston) 3' end-labeled EcoRI and MseI primers with three selective nucleotides (designated E for EcoRI and $\mathrm{M}$ for $\mathrm{Mse}$ ) using a "touchdown" procedure. The primer combinations and their selective nucleotides used in this analysis were E-ACC + M-CAT, E-AGA + M-CAC, E-AGG + M-CAC, E$\mathrm{AGG}+\mathrm{M}-\mathrm{CAT}$, and E-ACG + M-CAT. Profiles were generated from DNA extracted from 71 SGFL individuals and 10 cowpea$S$. gesnerioides individuals. In addition, DNA isolated from 20 individual S. gesnerioides plants parasitic on I. hirsuta collected from Pahou, Benin Republic $\left(6^{\circ} 23.14^{\prime} \mathrm{N}\right.$ and $\left.2^{\circ} 13.17^{\prime} \mathrm{E}\right)$ were included in the analysis. The $S$. gesnerioides plants parasitic on I. hirsuta from West Africa are collectively designated as SGIA.

Preparation of host and nonhost root exudates and germination stimulation assays. Preconditioning of Striga seed from central Florida (SGFL) and West Africa (SG1 from Burkina Faso, SG3 from Nigeria, SG4 from Benin, and SG5 from Cameroon) was carried out essentially as previously described $(1,3)$. The seed were surface sterilized in a solution of $1 \%$ sodium hypochlorite for $5 \mathrm{~min}$, rinsed with distilled water, and then placed in a benomyl solution at $100 \mu \mathrm{g} / \mathrm{ml}$ for $30 \mathrm{~min}$. This was rinsed five times with distilled sterile water. Striga seed then were soaked in distilled water in petri dishes sealed with parafilm. Petri dishes were wrapped in aluminum foil and placed in the incubator at $28^{\circ} \mathrm{C}$. Seed were sonicated using a W-220 sonicator (Heat Systems-Ultrasonics, Inc., Farmingdale, NY) for $60 \mathrm{~s}$ and the water replaced with fresh distilled water every other day for over a period of 14 days.

Host root exudates were obtained from 12-day-old cowpea plants and 21-day-old Indigofera plants growing in vermiculite by washing the roots of 10 to 15 plants (per 6-in. plastic pot) with $250 \mathrm{ml}$ of distilled water. In each case, the percolated water was collected in a beaker and then filter-sterilized using Nalgene disposable filter units (Nalge Nunc International, Rochester, NY) with a pore size of $0.45 \mu \mathrm{m}$. Root exudates were stored at $4^{\circ} \mathrm{C}$ until used. Prior to the exposure of the Striga seed to the root exudate, the seed were further surface sterilized with $25 \%$ ( $\mathrm{vol} / \mathrm{vol}$ ) commercial bleach for $15 \mathrm{~s}$ and rinsed five times with distilled sterile water. In all, $\approx 150$ preconditioned Striga seed were placed in culture plates in three replications, and allowed to air dry in a laminar hood for $25 \mathrm{~min}$. This was followed by the addition of $150 \mu \mathrm{l}$ of root exudates, sealed with parafilm and then wrapped with aluminum foil. These set-ups then were placed in the incubator at $28^{\circ} \mathrm{C}$ for 3 days, after which germinated and ungerminated seed were counted using a light microscope. Sterile distilled water was used in place of host roots exudates as control.

Analysis of host- and nonhost-parasite interactions. In order to evaluate for the pathogenicity of the SGFL strain with cowpea, a second series of pot trials was set up in which seed of the four populations (SGFL1 through SGFL4) were used to infest pots planted with two cowpea genotypes, TVX-3236 and Blackeye, known to be susceptible to all races of $S$. gesnerioides parasitic on cowpea in West Africa (5). Pot trials involving the cowpea-specific strains SG1, SG3, SG4, and SG5 with TVX-3236 
and Blackeye, and SGFL with I. hirsuta interaction, were included as controls. The experiments were set up in a completely randomized design with three replications and repeated three times.

Number of parasite attachments and Striga emergence data were recorded at 10 weeks postinfestation or planting for $S$. gesnerioides-cowpea set-ups (compatible interaction), and at 16 weeks for I. hirsuta plants infected with cowpea-adapted $S$. gesnerioides strains (incompatible interaction), and for the I. hirsuta plants infected with Indigofera-adapted S. gesnerioides (SGFL) (compatible interaction). Set-ups were sampled destructively to evaluate for postattachment interaction. The plant-per-soil mass from each pot was removed and immersed in a bucket of water, then agitated gently to loosen the soil mass off the host roots. Roots of the infested cowpea and I. hirsuta plants were washed free of soil and then examined under a dissecting microscope for attached Striga spp., necrotic hypersensitive lesions, and tubercles.

Histological analysis. Thin sections $(25 \mu \mathrm{M})$ of Striga tubercles were prepared from samples taken from each of the three types of Striga-host interactions described above. Specimens were sectioned using a freezing microtome (cryostat) at $-26^{\circ} \mathrm{C}$ after fixing the specimen in tissue freezing medium (Triangle Biomedical Sciences, Durham, NC). Sections were stained with phloroglucinol $(10 \mathrm{mg} / \mathrm{ml})$ and visualized with the aid of a light microscope mounted with a Leica DC 200 digital camera. Images were captured at a resolution of 1,900 by 1,200 pixels.

Statistical analysis. Data from the germination assay and Striga spp. emergence counts each were subjected to analyses of variance (ANOVA) by the GLM procedure of the Statistical Analysis System (SAS, rel. 8.2; SAS Institute Inc., Cary, NC). ANOVA was done with square root-transformed values for the germination assay. For the Striga spp. emergence data, a constant was added in order to normalize data sets with values of zero prior to ANOVA. Separation of treatment means was done by the least significance difference.

Bands in the AFLP profiles of each individual plant were scored as present or absent ( 1 or 0 , respectively) and subjected to sequential clustering algorithm using the unweighted pairgroup method with arithmetic means (UPGMA) (38). The relationships within populations and within and among different collections and strains of $S$. gesnerioides were generated using the phylogenetic analysis using parsimony (PAUP) software (version 4.0b10) (39) and presented in a dendrogram. The reliability of each cluster in the dendrogram showing plant-to-plant relatedness was confirmed by bootstrap analysis (14) with 1,000 replications using PAUP. Genetic distances were estimated using PAUP, applying pairwise comparison as described previously (29). The formula used was $G d x y=1-[2 N x y /(N x+N y)]$, where $N x y$ is the number of fragments shared between individuals $x$ and $y$ and $N x$ and $N y$ are the total number of fragments scored in $x$ and $y$, respectively. Genetic distances are defined on a scale ranging from 0.00 (when all the bands for any two individuals are identical) to 1.00 (when the bands for any two individuals are all different).

\section{RESULTS}

Genetic distances and phenetic relationships. In order to evaluate the intra- and interpopulation genetic structure of $S$. gesnerioides parasitic on I. hirsuta (SGFL) in central Florida, and the relationship of this strain to other $S$. gesnerioides strains, AFLP profile analysis was carried out using five different combinations of EcoRI- and MseI-selective primers. In all, 71 plants representing four different populations, SGFL1 to SGFL4, were evaluated along with individuals from $S$. gesnerioides populations parasitic on I. hirsuta from Benin, West Africa (SGIA) and individuals representative of different races of $S$. gesnerioides parasitic on cowpea from West Africa (e.g., SG1, SG3, and so on). The number of scorable AFLP markers ranged from 87 (E-AGA + MCAC) to 148 (E-ACC + M-CAT) and, in all, 680 fragments were scored from analysis using five different EcoRI- and MseIselective primer combinations.

Over $98 \%$ of all the bands scored were identical among the 71 individual SGFL plants evaluated. Pairwise genetic distances between individuals within the SGFL1, SGFL2, SGFL3, and SGFL4 populations ranged from 0.000 to 0.067 . Genetic distances between the individuals from the four SGFL populations and SGIA ranged from 0.240 to 0.330 . Slightly lower genetic distances (ranging from 0.214 to 0.274 ) were found between Striga seedlings parasitic on cowpea and I. hirsuta from West Africa (SGIA). The largest pairwise genetic distances were obtained between individuals in the SGFL populations and those parasitic on cowpea from West Africa, with values ranging from 0.320 to 0.390 .

Each of the five primer combinations used in this study readily generated at least one marker fragment that discriminated between $S$. gesnerioides strains parasitic on Indigofera spp. (SGFL) and those parasitic on cowpea. The EcoRI- and MseI-selective primer combination E-AGG + M-CAC generated a fragment of $\approx 510 \mathrm{bp}$ that was present in SGFL individuals and the West African isolate parasitic on I. hirsuta (SGIA), but absent in S. gesnerioides representative of the races of the parasite that parasitize cowpea in West Africa. The primer combination E-AGA + MCAC generated fragments of $\approx 415,435$, and 465 bp that discriminated the cowpea-S. gesnerioides interaction from all four SGFL populations (i.e., SGFL1 through SGFL4).

The phenetic relationships among SGFL, SGIA, and cowpea$S$. gesnerioides are shown in Figure 1. Two major clusters are formed, with all individuals in the SGFL1, SGFL2, SGFL3, and SGFL4 populations forming one cluster, and SGIA and cowpea$S$. gesnerioides the other. The cowpea-S. gesnerioides from West Africa is the most distantly related of the forms analyzed. Genetically, cowpea-S. gesnerioides is more similar to SGIA (parasitic on I. hirsuta from West Africa) than any of the populations (SGFLs) parasitic on I. hirsuta in the United States.

Germination stimulation and postattachment development on host and nonhost species. To evaluate the host-parasite interactions, germination stimulation assays and pot tests of parasite growth and emergence were carried out on host and nonhost plants (i.e., Indigofera spp. and cowpea). The mean percent germination following $72 \mathrm{~h}$ of exposure is presented in Table 1. Germination was observed in all combinations of host root exudates and parasite seed tested, with root exudates from the cowpea genotypes (Blackeye and TVX-3236) and I. hirsuta stimulating seed germination of both SGFL and SG1-5. The differences in the level of germination were highly significant $(P=0.01)$, with cowpea-S. gesnerioides race $S G 5$ from Cameroon and root exudates from cowpea $\mathrm{cv}$. Blackeye having the highest germination (97\%). Of the $S$. gesnerioides races parasitic on cowpea, $S G 3$ from Nigeria showed the lowest germination response to root exudates from $I$. hirsuta (66\%). All the control germination assays using sterile distilled water in place of the root exudates produced no germination.

The number of emerged Striga plants following parasitism on cowpea and $I$. hirsuta was significantly different $(P=0.01)$, with absolute values ranging from 9.0 (cowpea-S. gesnerioides race SG1 from Burkina Faso and I. hirsuta combination) to 96.0 (cowpea-S. gesnerioides race SG5 from Cameroon on TVX-3236 combination) (Table 2). The Striga spp. emergence count for all combinations with cowpea cv. Blackeye was low relative to the level of germination stimulated by root exudates from this genotype, when compared with a corresponding data set for TVX3236 (Tables 1 and 2). Interestingly, although cowpea genotypes Blackeye and TVX-3236 are known to be susceptible to all races of $S$. gesnerioides from West Africa, and could stimulate germination of Indigofera-S. gesnerioides (SGFL) seed from central 
Florida (Table 1), no Striga spp. emergence was recorded for any of the combinations, Blackeye and SGFL or TVX-3236 and SGFL (Table 2). Postattachment evaluations of all interactions in the combinations Blackeye + SGFL and TVX-3236 + SGFL showed that the development of attached SGFL Striga plants on these cowpea genotypes is arrested after tubercle formation (Fig. 2B). In the compatible interactions involving cowpea-S. gesnerioides from West Africa with cowpea genotypes Blackeye and TVX-3236 (Fig. 2A), and S. gesnerioides strain SGFL from central Florida with I. hirsuta (Fig. 2C), the development of attached $S$. gesnerioides plants progressed to the completion of the life cycle.

Histological analysis of tubercles formed in compatible and incompatible interactions. To further evaluate the nature of the
TABLE 1. Germination of Striga gesnerioides seed after $72 \mathrm{~h}$ of exposure to root exudates from two cowpea genotypes (Blackeye and TVX-3236) and Indigofera hirsuta

\begin{tabular}{lcccc}
\hline & & \multicolumn{3}{c}{ Host root exudate, mean germination $(\%)^{\mathrm{z}}$} \\
\cline { 3 - 5 } Source country & Race, strain & Blackeye & TVX-3236 & I. hirsuta \\
\hline Burkina Faso & SG1 & $92 \mathrm{ab}$ & $94 \mathrm{ab}$ & $72 \mathrm{~d}$ \\
Nigeria & SG3 & $96 \mathrm{a}$ & NA & $66 \mathrm{~d}$ \\
Benin Republic & SG4 & $72 \mathrm{~d}$ & $86 \mathrm{bc}$ & $87 \mathrm{bc}$ \\
Cameroon & SG5 & $97 \mathrm{a}$ & NA & $90 \mathrm{abc}$ \\
United States & SGFL & $83 \mathrm{c}$ & $92 \mathrm{ab}$ & $96 \mathrm{a}$ \\
\hline
\end{tabular}

${ }^{\mathrm{z}}$ Means followed by the same letter in the same column are not significantly different $(P=0.01$, least significant difference). NA $=$ data not available.

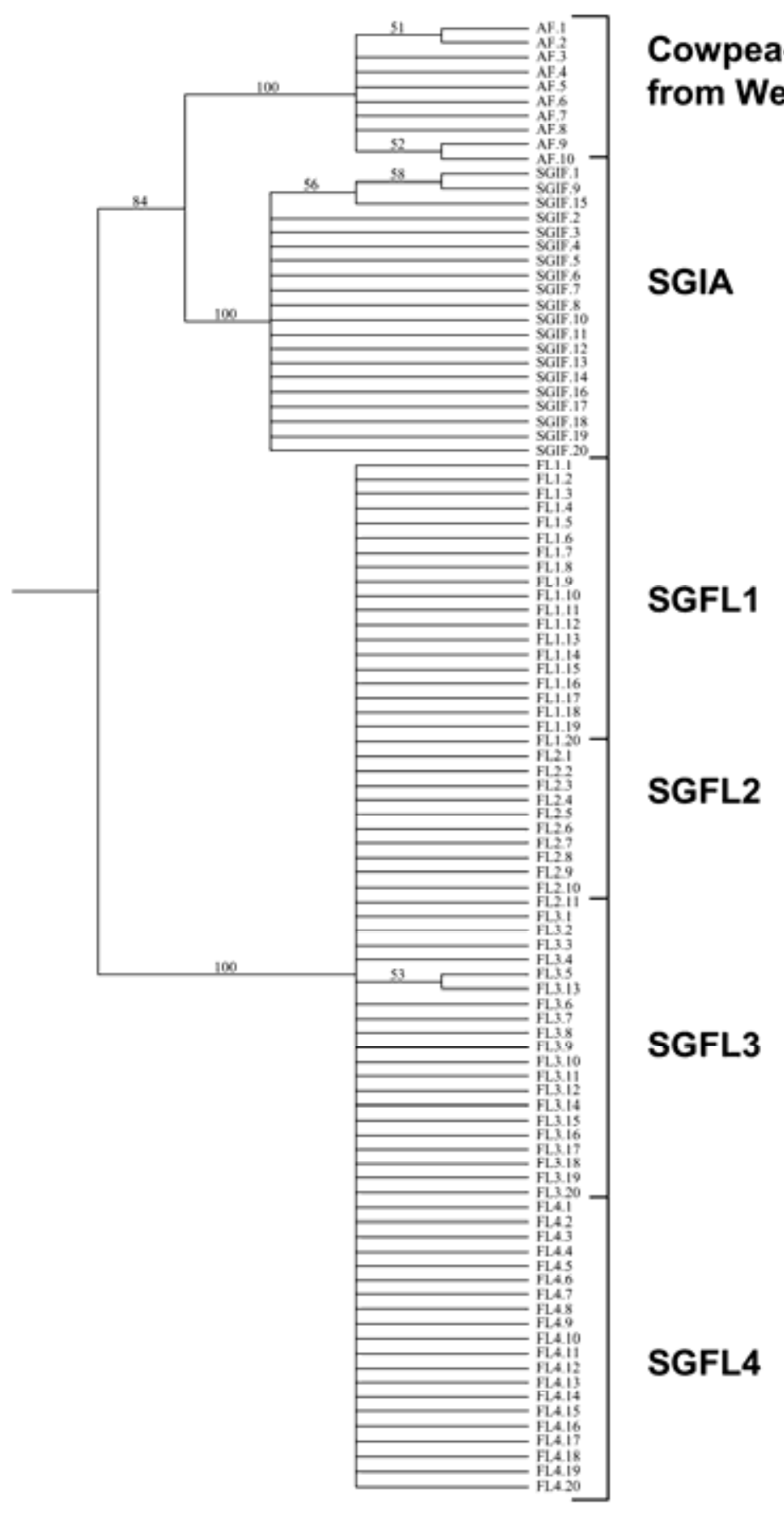

Fig. 1. Dendrogram showing the phenetic relationship among different strains of Striga gesnerioides parasitic on Vigna unguiculata (cowpea-S. gesnerioides from West Africa), and Indigofera hirsuta (SGIA from West Africa and the United States [SGFL1 through SGFL4]). Dendrogram was generated as described in Materials and Methods, and based on amplified fragment length polymorphism profile analysis data of individual S. gesnerioides plants obtained using five EcoRI- and MseI-selective primer combinations. Bootstrap values are indicated at each branch node. 
host-parasite interactions, histological studies were carried out on thin sections prepared from tubercles obtained from a compatible interaction involving the Striga spp.-susceptible cowpea cv. Blackeye and $S$. gesnerioides race 3 (SG3 from Nigeria), and an incompatible interaction involving cowpea cv. Blackeye and S. gesnerioides strain SGFL (from Florida). In contact with a susceptible host plant such as Blackeye, SG3 penetrates the host root cortex, develops a tubercle, and forms xylem-xylem linkage with the host vascular system. Tubercles from such interactions (Fig. 3A and C) show organized vascular tissues that extend to the developing cotyledons. In contrast, in incompatible interactions, such as that occurring when the Indigofera spp.-adapted strain SGFL attempts to parasitize the highly SG3-susceptible cowpea cv. Blackeye, development of the parasite is arrested at tubercle formation. Although a tubercle develops, it appears to lack internal organization and there is no evidence of either vascular development or connection between parasite and host (Fig. 3B and D).

TABLE 2. Number of emerged Striga gesnerioides plants following parasitism on two cowpea genotypes (Blackeye and TVX-3236) and Indigofera hirsuta

\begin{tabular}{lcccc}
\hline & & \multicolumn{3}{c}{ Mean Striga spp. emergence ${ }^{\mathrm{z}}$} \\
\cline { 3 - 5 } Source country & Race, strain & Blackeye & TVX-3236 & I. hirsuta \\
\hline Burkina Faso & SG1 & $18 \mathrm{ef}$ & $73 \mathrm{~b}$ & $9 \mathrm{~g}$ \\
Nigeria & SG3 & $23 \mathrm{~d}$ & $54 \mathrm{c}$ & $13 \mathrm{fg}$ \\
Benin Republic & SG4 & $29 \mathrm{~d}$ & $80 \mathrm{ab}$ & $22 \mathrm{de}$ \\
Cameroon & SG5 & $27 \mathrm{~d}$ & $96 \mathrm{a}$ & NA \\
United States & SGFL & $0 \mathrm{~h}$ & $0 \mathrm{~h}$ & $24 \mathrm{~d}$ \\
\hline
\end{tabular}

${ }^{\mathrm{z}}$ Means followed by the same letter in the same column are not significantly different $(P=0.01$, least significant difference). $\mathrm{NA}=$ data not available.

\section{DISCUSSION}

The level of genetic uniformity reported here within and among different collections of Indigofera-S. gesnerioides (SGFL) from central Florida is very high. The extremely low genetic variation, with pairwise genetic distances between individuals ranging from 0.000 to 0.037 , may be attributed to a number of factors. First, the species is autogamous, with a floral biology that makes any possibility for outcrossing very low. Unlike most other Striga spp. where powdery pollen is formed, $S$. gesnerioides produces pollen plugs and, thus, genetic variation that may result from outcrossing is practically impossible. With autogamy, it would be expected that even a single Striga sp. seed that successfully parasitizes a host could colonize a given locality readily, whereas minor variations rapidly become genetically fixed, and allele frequencies would be either 1 or 0 . Apart from the very strong autogamous mode of reproduction, Indigofera witchweed from central Florida is isolated from its counterparts in Africa and Asia, so that changes of population structure or composition through mechanisms such as gene flow is highly restricted. It is likely that SGFL became established in the five counties in central Florida following a single introduction in Polk County and then spread to other counties with time, possibly with Indigofera seed. It might well be that there were multiple introductions that experienced a hostdriven selection leading to genetic uniformity in this strain of the parasite. SGFL has been reported to parasitize mainly I. hirsuta in five counties in central Florida (28). We have shown that race formation in cowpea-S. gesnerioides was largely a result of hostdriven selection (5). Given that SGFL shares a common marker fragment $(510 \mathrm{bp})$ with the $S$. gesnerioides isolate from West Africa that parasitized I. hirsuta, it is likely that SGFL experi-

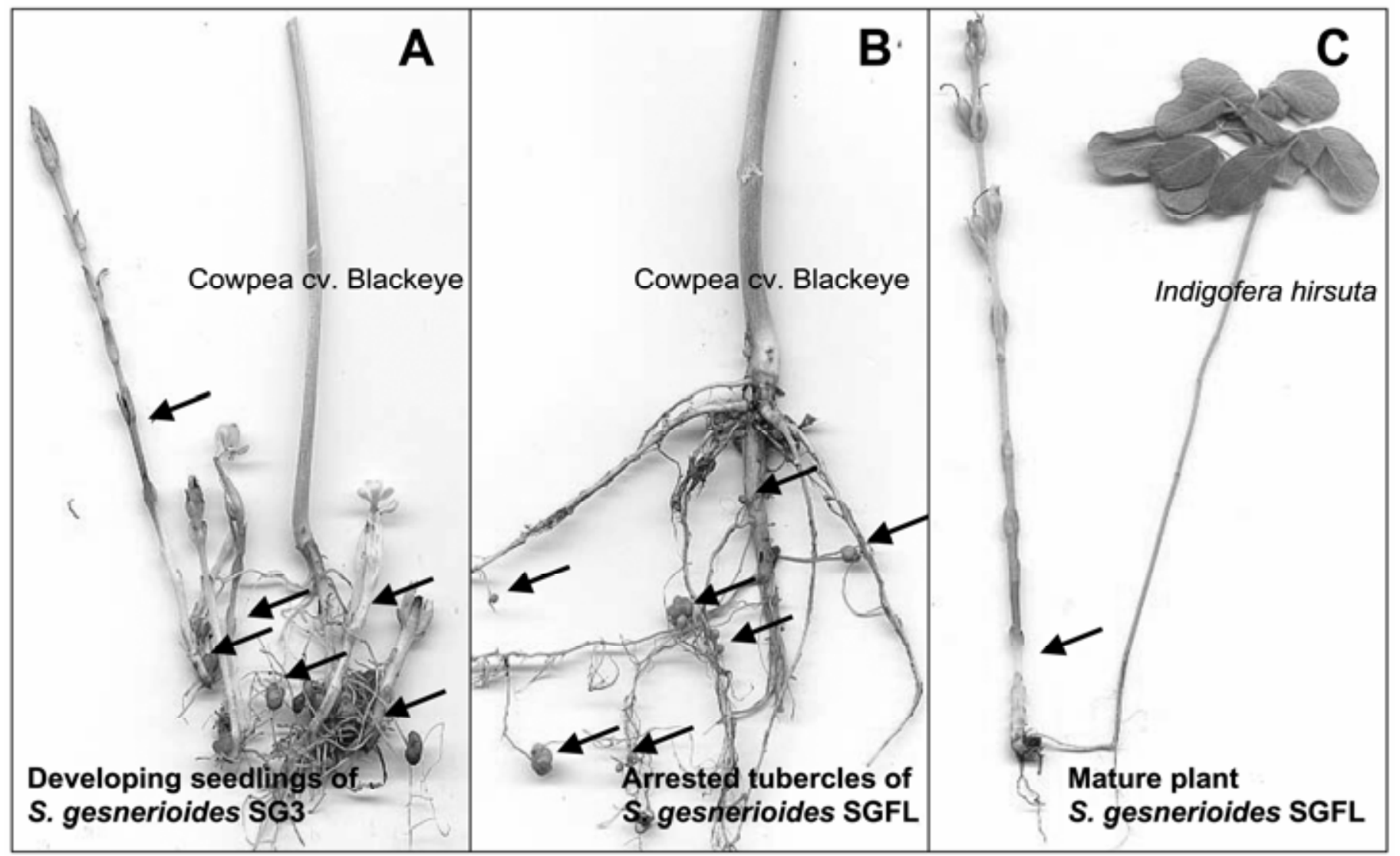

Fig. 2. Representative post-attachment interactions between two strains of Striga gesnerioides host and nonhost species. A, S. gesnerioides race SG1 from Burkina Faso developing on the susceptible cowpea cv. Blackeye. Arrows indicate various individual Stritga seedlings. B, S. gesnerioides strain SGFL, adapted for growth on Indigofera hirsuta growing on the susceptible cowpea cv. Blackeye. Arrows indicate various attached Striga seedlings arrested at the tubercle stage of development. C, S. gesnerioides strain SGFL developing on its host, I. hirsuta. 
enced a host-driven selection to genetic uniformity. Jerome and Ford (23) showed that host identity (host-driven selection), among other factors, contributed to race formation in dwarf mistletoe (Arceuthobium americanum). Allozyme analysis of S. asiatica collected from well-separated locations within North and South Carolina showed that the populations were monomorphic at 32 genetic loci encoded by 18 different isoenzymes (43). Pavlista (32) suggested that the establishment of S. asiatica in the United States likely involved one or a few seed which, in conjunction with low recombination rate, may have led to the rapid loss of variation during early stages of the infestation.

How $S$. gesnerioides was introduced into the United States remains unknown. One possibility is that seed of the parasite were present as contaminants in I. hirsuta seed (28). As a result of its ability to fix nitrogen, I. hirsuta currently is being used for the reclamation of phosphate mining sites in central Florida. Unlike $S$. asiatica, which was first reported in the United States in 1956, spread rapidly, and was considered a major threat to U.S. agriculture (17), S. gesnerioides thus far has not achieved agronomic significance in the United States. In fact, despite the lack of any conscious effort at containment, there is little evidence for spread of the parasite outside of the initial infestation areas. This may be the result of the very narrow host range exhibited by the SGFL strain. We recently observed that $S$. gesnerioides seedlings growing on I. hirsuta in a farmer's field in West Africa were able to parasitize cowpea under laboratory conditions (5). With increased disturbance throughout central Florida as a result of natural disasters such as hurricanes, the spread of SGFL seed to areas under intensive agricultural use is enhanced. Thus, the potential for this species to shift host and become a threat to U.S. agriculture exists.

The ability of nonhost species to stimulate the germination of $S$. gesnerioides has been described previously by Berner and Williams (3). These authors showed that a cultivar of Sorghum bicolor (a nonhost species) stimulated significantly more germination of Striga gesnerioides than any other species, including various Vigna spp. This is the basis for suicidal or abortive germination of Striga seed, a measure that is being used for the control of Striga spp. in many parts of the world $(3,6,9,11)$. It also has been reported that exudates from cowpea stimulated the germination of a strain of $S$. gesnerioides that parasitize small-flower
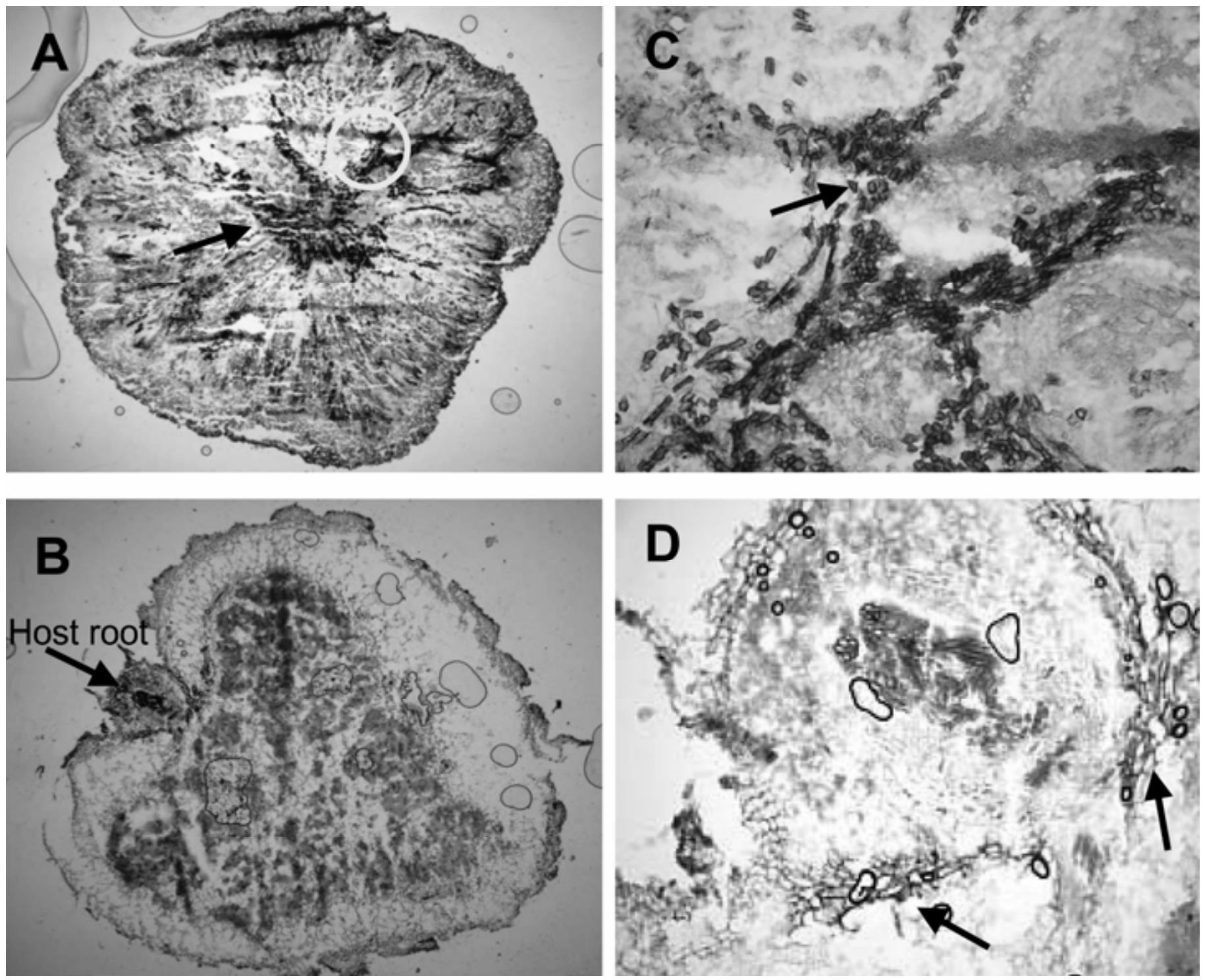

Fig. 3. Vascular organization at the host-parasite interface in Striga gesnerioides tubercles of compatible and incompatible interactions. Thin sections were prepared from tubercles from the roots of A and C, the susceptible cowpea cv. Blackeye parasitized by SG3 or B and D, Blackeye parasitized by SGFL. Sections were stained with phloroglucinol and visualized by light microscopy. A, Arrow indicates the organized central vascular tissue in compatible host-parasite interactions. C, A portion of this vascular core showing developed vessel elements is magnified. B, A corresponding lack of organized vascular tissue in the tubercle formed in an incompatible interaction. D, A close-up of the host-parasite interface. Note the intact host vascular bundle unconnected to the parasite. Arrows indicate where lignification of host cells has occurred at the interface. 
morning glory but failed to parasitize cowpea (30). Our data clearly show that selection of a host by $S$. gesneroides is not mediated solely by response to host-derived germination stimulants because root exudates from all the species tested elicited germination of Striga seed (Table 1). Our findings indicated that developmental processes occurring postgermination and attachment are likely more important in limiting successful host-parasite interaction. Musselman and Parker (28) previously have reported that SGFL failed to parasitize cowpea, but did not explore the causative effect of this failure. Here we demonstrate that the inability of Indigoferaadapted SGFL to parasitize cowpea results from incompatibility between parasite and host that commences postattachment.

The cowpea genotypes Blackeye and Tvx3236 are susceptible to all known races of $S$. gesnerioides from West Africa, but resistant to parasitism of SGFL. In compatible interactions, as in the case of SG3 with Blackeye, following parasite attachment, rapid connection of the parasite and host vascular systems occurs through xylem-xylem linkage. Once the vascular connection is established, the parasite uses this connection to divert host resources (water and other nutrients) (34). In the SGFL-Blackeye interaction, incompatibility appears to be the result of the failure of the parasite to establish proper vascular connection with the host. Why this connection is not established, despite the fact that the parasite has attached and begun to develop its tubercle, remains unclear. One possibility is that there is an improper exchange of developmental cues from host to parasite directing its development. It also is possible that, in the absence of a specific gene-for-gene resistance response (found when a resistant cowpea cultivar is parasitized by a specific race of $S$. gesnerioides), a default nonhost resistance or basal resistance response is mounted, leading to cessation of further invasion by the parasite and arrest of parasite development.

It is interesting that, in the incompatible interactions, tubercle development proceeds and that the tubercle is able to survive for several weeks without a connection with the host vascular system. It has been reported that, in Orobanche spp., a parasite related to Striga spp., high amounts of mannitol accumulate and thus lower the osmotic potential to a value much more negative than that of the host (21). Thus, it is believed that inhibitors of mannose 6-phosphate reductase (a key enzyme in mannitol biosynthetic pathway) would control Orobanche spp. during the early stages of development (12). It is plausible that, despite not establishing vascular connections, the tubercles develop for a short period of time in the incompatible interactions between cowpea and SGFL by maintaining a higher osmotic potential (more negative) than that found in the host. Once the lack of vascular connection becomes limiting, tubercle growth ceases. Metabolic profiling or the identification and characterization of genes that are differentially expressed following compatible and incompatible interaction of $S$. gesnerioides and its host or nonhost will illuminate these process further and may provide a key to identifying potential inhibitors of genes or metabolic pathways that are involved in compatible interactions.

\section{ACKNOWLEDGMENTS}

This work was supported by funds from the NSF (IBN-0322420) and a USAID Linkage Grant with the International Institute of Tropical Agriculture awarded to M. P. Timko. We thank L. J. Musselman (Old Dominion University), B. Wise, and R. C. Garcia (Mosaic Co.) for their invaluable assistance during the collection of Striga gesnerioides seed in central Florida; and A. Erisir and B. Goodwin (Department of Psychology, University of Virginia) for their assistance during histological analysis.

\section{LITERATURE CITED}

1. Aggarwal, V. D. 1985. Cowpea Striga research. Pages 335-340 in: Cowpea Research, Production, and Utilization. S. R. Singh and K. O. Rachie, eds. John Wiley \& Sons, London.
2. Babiker, A. G. T., Ejeta, G., Butler, L. G., and Woodson, W. R. 1993. Ethylene biosynthesis and strigol-induced germination of Striga asiatica. Plant Physiol. 88:359-365.

3. Berner, D. K., and Williams, O. A. 1998. Germination simulation of Striga gesnerioides seeds by hosts and nonhosts. Plant Dis. 82:12421247.

4. Boone, L. S., Fate, G., Chang, M., and Lynn, D. G. 1995. Seed germination. Pages 14-38 in: Parasitic Plants. M. C. Press and J. D. Graves, eds. Chapman \& Hall, London.

5. Botanga, C. J. 2005. Genetic and molecular analyses of factors defining host-specificity and virulence in Striga species (Scrophulariaceae). Ph.D. dissertation, University of Virginia, Charlottesville.

6. Botanga, C. J, Alabi, S. O., Echeckwu, C. A., and Lagoke, S. T. O. 2003. Genetics of suicidal germination of Striga hermonthica (Del.) Benth by cotton. Crop Sci. 43:438-488.

7. Butler, L. G. 1995. Chemical communication between parasitic weed, Striga and its host crop: A new dimension in allelochemistry. Pages 156168 in: Allelopathy: Organisms, Process, and Applications. K. M. Inderjit, M. Dakshini, and F. A. Einhelling, eds. ACS Symp. Ser. 582, American Chemical Society, Washington, DC.

8. Cai, T., Babiker, A. G., Ejeta, G., and Butler, L. G. 1993. Morphological response of witchweed (Striga asiatica) to in-vitro culture. J. Exp. Bot. 44:1377-1384.

9. Carson, A. G. 1988. Studies on Striga in Gambia. Pages 37-43 in: Proc. FAO/OAU All-African Government Consultation on Striga Control. T. O. Robson and H. R. Broad, eds. FAO, Rome.

10. Chang, M., and Lynn, D. G. 1986. Haustoria and the chemistry of host recognition in parasitic angiosperms. J. Chem. Ecol. 12:561-579.

11. Dejongh, K., Van Damme, P., and Berner, D. K. 1993. Suicidal germination of Striga seed using several trap crop varieties. Meded. Fac. Landbouwwet. Rijksuniv. Gent. 58(3a.):983-993.

12. Devault, P., Simier, P., Séverine, T., Véronési, C., Fer, A., and Thalouarn, P. 2002. Isolation of manose-6-phosphate reductase cDNA, changes in enzyme activity and manitol content in broomrape (Orobanche ramose) parasitic on tomato roots. Physiol. Plant. 115:48-55.

13. Dörr, I. 1997. How Striga parasitizes its host: ATEM and SEM study. Ann. Bot. 79:463-472.

14. Efron, B., and Gong, G. 1983. A leisure look at the bootstrap, the jackknife, and cross-validation. Am. Stat. 37:36-48.

15. Efron, Y., Kim, S.K., Parkinson, V., and Boxque-Perez, N. A. 1988. IITA's strategies to develop Striga resistant maize germplasm. Pages 141-153 in: Proc. FAO/OAU All-African Government Consultation on Striga Control. T. O. Robson and H. R. Broad, eds. FAO, Rome.

16. Emechebe, A. M., Singh, B. B., Leleji, O. I., Atokple, I. D. K., and Adu, J. K. 1991. Cowpea-Striga problems and research in Nigeria. Pages 18-28 in: Combating Striga in Africa. S. K. Kim, ed. Proc. Int. Workshop organized by IITA, ICRISAT and IDRC. IITA, Ibadan, Nigeria.

17. Eplee, R. E. 1992. Witchweed (Striga asiatica): An overview of management strategies in the USA. Crop Prot. 11:3-7.

18. Estabrook, E. M., and Yoder, J. I. 1998. Plant-plant communications: Rhizosphere signaling between parasitic angiosperms and their hosts. Plant Physiol. 116:1-7.

19. Graves, J. D., Press, M. C., Smith, S., and Stewart, G. R. 1992. The carbon canopy economy of the association between cowpea and the parasitic angiosperm Striga gesnerioides. Plant Cell Environ. 15:283-288.

20. Graves, J. D., Press, M. C., and Stewart, G. R. 1989. A carbon balance model of the sorghum-Striga hermonthica host-parasite association. Plant Cell Environ. 12:101-107.

21. Harloff, H. J., and Wegmann, K. 1987. Manitol pathway in Orobanche. Pages 295-308 in: Proc. Fourth Int. Symp. Parasitic Flowering Plants. H. C. Weber and W. Forstreuter, eds. Phillips University, Marburg.

22. Herbaugh, L., Upton, N. P., and Eplee, R. E. 1980. Striga gesnerioides in the United States of America. Proc. South. Weed Sci. Soc. 33:187-190.

23. Jerome, C. A., and Ford, B. A. 2002. The discovery of three genetic races of the dwarf mistletoe (Arceuthobium americanum [Viscaceae]) provides insight into the evolution of parasitic angiosperms. Mol. Ecol. 11:387-405.

24. Lagoke, S. T. O., Parkinson, V., and Agunbiade, R. M. 1991. Parasitic weeds and control methods in Africa. Pages 3-14 in: Combating Striga in Africa. S. K. Kim, ed. Proc. Int. Workshop organized by IITA, ICRISAT and IDRC. IITA, Ibadan, Nigeria.

25. Lane, J. A., Moore, T. H. M., Child, D. V., and Cardwell, K. F. 1996. Characterization of virulence and geographic distribution of Striga gesnerioides on cowpea in West Africa. Plant Dis. 80:299-301.

26. Mohamed, K. I., Musselman, L. J., and Riches, C. R. 2001. The genus Striga (Scrophulariaceae) in Africa. Ann. Mo. Bot. Gard. 88:60-103.

27. Musselman, L. J. 1980. The biology of Striga, Orobanche and other rootparasitic weeds. Annu. Rev. Phytopathol. 18:463-489.

28. Musselman, L. J., and Parker, C. 1981. Studies on Indigo witchweed, the American strain of Striga gesnerioides (Scrophulariaceae). Weed Sci. 29:594-596. 
29. Nei, M., and Li, W.-H. 1979. Mathematical model for studying genetic variation in terms of restriction endonucleases. Proc. Natl. Acad. Sci. USA 76:5269-5273.

30. Parker, C., and Reid, D. C. 1979. Host specificity in Striga species-some preliminary observations. Pages 79-90 in: Proc. 2nd Symp. Parasitic Weeds. L. J. Musselman, A. D. Worsham, and R. E. Eplee, eds. North Carolina State University, Raleigh.

31. Parker, C., and Riches, C. R. 1993. Striga and Alectra on cowpea and other broadleaved crops. Pages 75-109 in: Parasitic Weeds of the World: Biology and Control. C. Parker and C. R. Riches, eds. CAB International, Wallingford, UK

32. Pavlista, A. D. 1981. Why hasn't witchweed spread in the United States? Weeds Today (special issue):16-19.

33. Pieterse, A. H. 1985. Control of Striga at the level of small-scale farmer. Pages 24-36 in: Proc. FAO/OAU Workshop on Striga. FAO, Rome.

34. Riopel, J. L., and Timko, M. P. 1995. Haustorial initiation and differentiation. Pages 29-79 in: Parasitic Plants. M. C. Press and J. D. Graves, eds. Chapman and Hall, London.

35. Rogers, W. E., and Nelson, R. R. 1962. Penetration and parasitism of Striga asiatica. Phytopathology 52:1064-1070.

36. Sahai, A., and Shivanna, K. R. 1982. Seed germination and seedling morphogenesis in parasitic angiosperms of the families Scrophulariaceae and Orobanchaceae. Seed Sci. Technol. 10:565-583.
37. Saunders, A. R. 1933. Studies in phanerogamic parasitism with particular reference to Striga lutea Lour. Ph.D. diss., University of Pretoria, South Africa.

38. Sneath, P. H., and Sokal, R. R. 1973. Numerical Taxonomy: The Principles and Practice of Numerical Classification. W. H. Freeman, San Francisco.

39. Swofford, D. L. 1999. PAUP: Phylogenetic Analysis Using Parsimony, version 4.0beta10. Sinauer Associates, Sunderland, MA.

40. Van Gysel, A., Cnops, G., Breyne, P., Van Montagu, M., and Cervera, M. 1998. Chromosome landing using AFLPTM-based strategy. Pages 305314 in: Arabidopsis Protocols. Methods in Molecular Biology, Vol. 82. J. Martinez-Zapater and J. Salnas, eds. Humana Press, Totowa, NJ.

41. Visser, J. 1981. South African Parasitic Flowering Plants. Juta \& Co. Ltd., Capetown, South Africa.

42. Vos, P., Hogers, R., Bleeker, M., Reijans, M., Van de Lee, T., Hornes, M. Frijters, A., Pot, J., Peleman, J., Kuiper, M., and Zebeau, M. 1995. AFLP: A new technique for DNA fingerprinting. Nucleic Acids Res. 23:4407-4414.

43. Werth, C. R., Riopel, J. L., and Gillespie, N. W. 1984. Genetic uniformity in an introduced population of witchweed (Striga asiatica) in the United States. Weed Sci. 32:645-648.

44. Worsham, A. D. 1987. Germination of "witchweed" seeds. Pages 45-61 in: Parasitic Weeds in Agriculture, Vol. 1, Striga. L. J. Musselman, ed. CRC Press, Boca Raton, FL. 